Agenda, Volume 5, Number 1, 1998, pages 25-36

\title{
A Strategic Behaviour Approach to Evaluating Competitive Conduct
}

\author{
Rhonda L. Smith and David K. Round
}

S ECTION 46 of the Trade Practices Act prohibits Australian firms which have a substantial degree of market power from taking advantage of that power for the purpose of hindering competition in a market, preventing entry or damaging a rival. One of the earliest and most influential trade practices decisions in Australia is the so-called $Q C M A$ case of 1976 , concerning a proposed merger of flour millers. Here, the Trade Practices Tribunal (now the Australian Competition Tribunal, ACT) determined a methodology for analysing competition issues which was subsequently adopted by the Trade Practices Commission (now the Australian Competition and Consumer Commission, ACCC) as well as by the Federal and High Courts.

The $Q C M A$ approach is to define the relevant market and then to assess whether the conduct at issue could result in an increase in market power and consequently a substantial lessening of competition. The approach is structural, based largely on the measurement of non-behavioural factors. The Tribunal concentrated on what can be called 'group-structural' features of the market because of its concern that, after a merger, the market could exhibit collusive tendencies as a result of increased concentration. The emphasis was on potential as well as actual substitute products and on the height of entry barriers. Little account was taken of the dynamic, rivalrous interaction between current sellers or between these incumbents and potential entrants. Much concern was expressed about the price effects of the merger; and price issues have dominated most of the subsequent applications of this methodology.

The $Q C M A$ methodology did refer to the broad dimensions of competition, including non-price elements; it was noted that 'there should be independent rivalry in all dimensions of the price-product-service packages offered to consumers and customers'. Nevertheless, dynamic non-price rivalry, which individual firms undertake

Rhonda Smith is a Commissioner of the Australian Competition and Consumer Commission. David Round is Associate Professor of Economics at the University of Adelaide and an Associate Commissioner of the Australian Competition and Consumer Commission. The opinions expressed in this article are those of the authors alone.

\footnotetext{
${ }^{1}$ Re Queensland Co-operative Milling Association Ltd., Defiance Holdings Ltd. (Proposed Mergers with Barnes Milling Ltd.) (1976) ATPR 40-012.

2

Ibid at 17,246 .
} 
in order to derive a sustainable competitive advantage over their rivals, received little attention both in this decision and in subsequent cases.

In this article, it is argued that analysis of the competitive impact of a firm's behaviour should be primarily considered within a non-structural framework which recognises that conduct can differ markedly between firms in the same structural environment, or can be similar between firms operating in quite different structural market conditions, depending on the firms' goals, strengths, weaknesses and strategic directions.

Without doubt, the $Q C M A$ model provided a relatively simple but effective means of assessing the implications of conduct in relation to the Trade Practices Act at a time when neither the Federal Court nor the legal profession had much experience in dealing with a statute which is a mix of economics and law. In addition, in 1976 markets were less concentrated than they are today, and business initiatives and the environment were considerably less dynamic. However, time and theory have overtaken the $Q C M A$ approach, which now has less relevance to any assessment of the misuse of market power or of competition generally.

\section{Strategic Conduct and Market Structure}

Since 1976, markets in Australia have become more oligopolistic, particularly as a result of the mergers and acquisitions of the 1980 s and the general rationalisation of the 1990s. The distinguishing feature of oligopolistic markets is not so much the number of market participants, or the extent of market concentration, or the precise height of barriers to entry, but rather a recognition by firms of their mutual interdependence and its associated uncertainty. However, the individual patterns of behaviour which follow from this recognition can differ greatly. Of two markets, one with only two participants and the other with considerably more but with otherwise similar structural conditions, the latter could display little competition while the former could be highly competitive. Indeed, within two markets with identical structural features, including firm numbers, behaviour could differ markedly. Structural analysis is insufficient. Something more is needed: an analysis of strategic behaviour.

Attention should be focused on rivalry between individual firms rather than on a structural concept of competition. An analysis of strategic behaviour by individual firms will assist in distinguishing competitive from anti-competitive conduct. In oligopolistic markets, strategic behaviour can alter market structure, for example by raising or creating entry barriers. Further, while one action or strategy on its own may appear to lessen (or not to lessen) competition, a firm's whole set of strategies may lead to the opposite outcome. This may be especially important in the context of s.46 of the Trade Practices Act, which covers misuse of market power, where purpose must be proved, even if by inference from conduct.

\section{What Is Strategic Behaviour?}

'Strategic behaviour' refers to actions which a firm takes to improve its competitive position relative to actual and potential rivals, in order to gain a permanent commer- 
cial advantage, thereby increasing its long-run profits. Carlton and Perloff (1994:382) refer to actions 'to influence the market environment and so increase profits'; while Martin (1993:46) refers to 'investment of resources for the purpose of limiting rivals' choices'. Strategic behaviour thus refers to conduct which is not economically inevitable, but which is the outcome of a conscious attempt to shape the firm's market environment to its own lasting advantage and to the competitive disadvantage of rivals.

There are two categories of strategic behaviour. 'Non-cooperative behaviour' occurs when a firm tries to improve its position relative to its rivals by seeking to prevent them from entering a market, to drive them out of business or to reduce their profits. 'Cooperative behaviour' occurs when firms in a market seek to coordinate their actions and therefore limit their competitive responses (this does not necessarily imply explicit agreement). Here, only non-cooperative strategic behaviour is considered.

It is primarily under oligopolistic market conditions that a firm has an incentive to alter its relative position through strategic behaviour. The firm recognises its interdependence and the need to take into account other firms' reactions when making its own decisions; but it also recognises that it is free to make decisions to alter its commercial environment. These strategies are revealed over time through investment and through tactical moves and countermoves. Strategic behaviour can be manifested in:

- entry deterrence, for example through output expansion, the deliberate creation of excess capacity, pricing just below the level which would encourage entry, acquisition of essential inputs, predatory pricing, raising rivals' costs, and making credible threats as to how the firm will react to entry;

- advertising and brand proliferation;

- $\quad$ R\&D and technology choice;

- tying consumers in various ways where switching costs are significant; and

- various long-term contracting devices. ${ }^{3}$

To engage in successful non-cooperative strategic behaviour, a firm must have some market power or advantage; it must be able to act before its rivals; and it must demonstrate credibly that it will follow its strategy regardless of the actions of its rivals (that is, it should be able to deter potential rivals by changing their beliefs about how aggressively it will behave in future).

Such conduct may not cause long-term damage to the competitive process if continual opportunities exist for all firms to initiate new bouts of strategic behaviour, and if they all have equal opportunity to initiate such actions. There is nothing wrong with

${ }^{3}$ Textbooks, especially older ones, often suggest that these types of conduct are practised only by dominant firms; but modern theory accepts that such conduct can be undertaken by firms with relatively modest degrees of market power. 
a firm seeking to get ahead of its rivals by developing a sustainable commercial superiority over them by, for example, developing better production techniques or introducing new and better products. This has been recognised by the High Court in Australia in the Queensland Wire case, where it was stated by Mason CJ and Wilson J that

Competition by its very nature is deliberate and ruthless. Competitors jockey for sales, the more effective competitors injuring the less effective by taking sales away. Competitors almost always try to 'injure' each other in this way. This competition has never been a tort ... and these injuries are the inevitable consequence of the competition s.46 is designed to foster.

\section{The Structuralist vs the Strategic Behaviour Approach}

The traditional structuralist approach and the strategic behaviour approach differ in several important ways. First, the structuralist approach is static, concentrating on two successive states of affairs but ignoning the process of the move from one to the other. It thus ignores the intertemporal issue usually associated with strategic behaviour. The strategic behaviour approach, in contrast, is dynamic and concentrates not only on conduct but also on responses to that conduct, and on the response to those responses, and so on, thus treating the firm as continually adapting to its environment.

Second, the structuralist approach tends to play down informational and demand asymmetries between firms, and the consequent differential expectations and the strategic responses which their existence may attract.

Third, while the adoption of new technology is accounted for in the structuralist model by downward movements of cost curves, in the strategic behaviour model it may also affect the conduct of one or more of the firms in the market.

Fourth, the strategic behaviour model tends to take a neutral view of firm size and market shares. While the structuralist approach may simply use market share as an indicator of the need to examine other structural factors, often size as such is taken to indicate the potential for collusion or misuse of market power: a line of reasoning that may be quite misleading in relation to oligopolistic markets.

Fifth, the structuralist model treats entry barriers as the most significant factor in assessing whether particular conduct is likely substantially to lessen competition in a market. In $Q C M A$, it was said that

Of all these elements of market structure, no doubt the most important is ... the condition of entry. For it is the ease with which firms can enter which establishes the possibilities of market concentration over time; and it is the

\footnotetext{
${ }^{4}$ Queensland Wire Industries Pty. Ltd. $v$ The Broken Hill Proprietary Company Limited \& Anor (1989) Australian Trade Practices Reports 40-925, at 50,010.

5 As suggested in the Merger Guidelines prepared by the ACCC (1996).
} 
threat of entry of a new firm or a new plant into a market which operates as the ultimate regulator of competitive conduct. ${ }^{6}$

The strategic behaviour model, meanwhile, places less significance on current barriers to entry (but by no means gives them an insignificant role) because, even in the absence of entry barriers, a firm may still seek to achieve a strategic advantage over its rivals by exclusionary or other behaviour which will create barriers to entry or expansion in the future. The absence of barriers to entry is therefore insufficient for establishing that conduct will not result in a substantial lessening of competition or in misuse of market power in the long run.

\section{Why a Framework Based on Strategic Behaviour?}

Whether strategic behaviour is anti-competitive in its effects depends on its nature and purpose. It may be socially acceptable under some market conditions but not under others. But the static, structural, group-centred approach based on QCMA is not really appropriate for fully analysing the anti-competitive effects of such conduct. Under that approach, if the structural features of the market do not appear likely to facilitate the exercise of market power, the conduct is generally not analysed further. However, the conduct in question may ultimately alter the market structure. Recent antitrust literature (see, for example, Baker, 1997) indicates that even firms with quite a small market share may exercise unilateral market power through strategic behaviour.

Not only has market structure become more oligopolistic, but business structures have become more complex. Most firms now operate in multiple markets that are linked in some way (for example, through common manufacturing or distribution processes, inputs or information) which provides synergies for the business as a whole. Thus, to understand conduct in any one market it may not be sufficient to look simply at the structure of that market in isolation.

Kay (1993:227-8), for example, suggests that firms should segment their markets (price discriminate) in order to appropriate added value most effectively. The firm should operate in as many markets as possible, given its competitive advantage. Pricing and marketing strategies should be designed to suit the characteristics of each market: for example, a firm might lower its prices in order to increase its market share so that it can earlier enjoy the size needed to undertake technological change. Firms can also engage in what might be called 'strategic packages', that is, a coordinated set of strategies jointly determined to further the multiple goals of the firm in one or all of its commercial environments. An example of this multiple-pronged strategic conduct is provided by the well-known du Pont case, where in order to derive a lasting commercial advantage in the market for titanium dioxide, the firm not only developed and patented a new, less polluting process, but at the same time greatly expanded production capacity such that it was capable of satisfying 95 per cent of forecast increases in demand. These actions significantly lowered du Pont's costs and it became the dominant firm. This illustrates what a firm can do to achieve lower costs and thereby derive

${ }^{6} Q C M A$, op. cit: 17,246 . This again emphasises the group-specific nature of the $Q C M A$ approach. 
a sustainable competitive advantage; but the package had the effect (and possibly the purpose) of market foreclosure.

The role of strategic behaviour within firms raises concerns not only in relation to identifying and pursuing breaches of Part IV of the Trade Practices Act, but also in relation to remedies for breach. Porter (1981:453) argues:

That an overall strategy guides strategic interaction also implies that a remedy aimed at one aspect of a firm's behaviour must be probed to see how it will affect the ability of the firm to carry out its previous strategy, and whether the firm is likely to adjust other elements of its strategy to compensate or redefine its strategy completely. The firm will strive to maintain an internally consistent approach to competing, and one to which it is uniquely suited.

An attempt by the ACCC or the ACT to correct behaviour in one market could thus have socially undesirable consequences in another, if firms pursue coordinated strategic behaviour across several markets. This problem is not new; but it needs to be addressed with a strategic behaviour approach to examining firm conduct.

\section{Some Examples of Strategic Behaviour}

One of the most difficult tasks for antitrust investigators is to determine, in the absence of 'the smoking gun', whether identical prices between rivals reflect successful collusion between them or are the outcome of genuine competition. Equally difficult is dealing with conduct such as alleged misuse of market power, where investigators confront the problem of distinguishing between action which is anti-competitive and (as it is usually characterised by the perpetrator) action which is pro-competitive. Some examples will illustrate this point.

In a Federal Court case involving a price war between an established suburban newspaper and a new entrant, the issue was whether the lowering of prices by the incumbent, the Wentworth Courier, was justifiable as a necessary competitive response to a new entrant, Eastern Express, with superior technology, or whether it was designed to drive out of the market an otherwise efficient rival. Alternatively, with just two participants in the market, did the new entrant have a strategy for driving the incumbent from the market? With existing technology, was the market large enough to sustain only one participant? Was the observed conduct by both parties that which could be expected to occur in a competitive market, or did it go beyond the boundaries of socially acceptable good, hard competition?

In a matter before the Trade Practices Tribunal in 1977, Ford sought approval for franchising restrictions which it wanted to impose on its dealers, arguing that it led to

7 See In the matter of E. I. du Pont de Nemours \& Company, 96 F.T.C. 653 (1980).

${ }^{8}$ Eastem Express Pty Limited v General Newspapers Pty Limited \& Ors (1991) Australian Trade Practices Reports 41-128. 
greater promotion and sales of Ford vehicles and therefore enhanced competition in the market. The Tribunal stated:

We reject the argument that an enhancement of competitive strength of a major participant in a market necessarily increases competition. To assess the effect on competition, it is essential to examine whether that enhancement has resulted from the imposition of a restraint on potential or existing competitors. Ford's argument would involve accepting that a dominant company which increased its competitive strength by weakening or eliminating its rivals was thereby increasing competition. Such action would increase that company's competitive position but instead of increasing competition in the industry concerned it would have the effect of decreasing competition.

Clearly all firms would like to secure from their rivals as many of the most suitable retailing outlets as possible, as this raises the costs of existing or new rivals and forces them to invest heavily in their own networks or to use less suitable alternative distribution outlets. But does this damage long-term prospects for competitive behaviour in the market? The Chicago school of economic thought would argue that such exclusive dealing is pro-competitive, as it enhances economic efficiency and promotes interfirm market rivalry. There is no clear-cut answer.

'Creeping acquisitions' have become increasingly common in Australia in recent years. Here a major player in a market gradually acquires smaller rivals, leading to an increase in the costs of competing for the remaining (smaller) rivals. A good example of this is the so-called 'cheque-book competition' by the major supermarket chains. The purchase of independent retailers does not appear substantially to lessen competition in the relevant market as numerous other retailers remain: that is, there has been no significant structural change in the market. However, if such purchases are part of a strategy to deprive independent wholesalers of access to key outlets or sales volume so that their average unit costs rise and their ability to compete with the chains is diminished, consideration of this activity under a strategic framework might well result in a different conclusion.

\section{Providing an Analytical Framework}

The following analysis provides a simplified example of how strategic behaviour might be assessed in practice.

In 1994 Rank Commercial Ltd, a New Zealand company, announced a takeover bid for the assets of Foodland Associated Limited (Foodland). An agreement be-

9 Ford Motor Company of Australia and Ford Sales Company of Australia Ltd. (1977) Australian Trade Practices Reports 40-043, at p. 17,498.

${ }^{10}$ For a summary of the arguments for and against vertical restrictions, see Carlton and Perloff (1994:522-44).

${ }^{11}$ We wish to thank Stephen King for his helpful suggestions on the presentation of this example. 
tween Rank and Coles Myer Limited (Coles) would have seen Foodland's Australian assets pass to Coles. Foodland at that time was the only wholesaler of groceries to independent retailers in Western Australia. It also owned a number of retail grocery stores operating under the Action banner. It was estimated that with the acquisition, Coles's share of grocery sales would have increased to 75 per cent (prior to the merger Coles's share was 23 per cent).

In order to analyse the proposed acquisition, the following assumptions are made:

- Significant economies of scale/scope exist in grocery wholesaling and retailing.

- Following the acquisition, Coles would obtain improved terms from its suppliers, if only because of the increased volume of purchases. Economies of scale, as well as pecuniary benefits, exist in obtaining grocery products from manufacturers.

- Barriers to entry into grocery wholesaling are high. A new independent wholesaler would be unlikely to set up in Western Australia if Coles were to exercise its market power following such an acquisition. Nor is there any real likelihood that the existing independent wholesaler in South Australia would sell into Western Australia.

- At the time of the proposed acquisition, Coles, Woolworths, Action Stores and the other independent retailers were competing strongly with each other for the retail supply of groceries to consumers.

After the acquisition, Coles would face the following options:

- Retain the cost savings from the acquisition (no price changes) and increase its profits.

- Use the reduction in supply costs to lower the prices to independent retailers and to Coles's own retail outlets (full pass through).

- Raise prices to the independent retailers in order to shift customers to its own retail outlets (this would also give some benefit to Woolworths). Coles's own prices might increase, decrease or remain constant. It is assumed that they remain constant, and that as a result Woolworths's prices are also unchanged.

Now consider whether the third option, raising rivals' costs, is rational. If Coles makes no changes, it benefits from the acquisition to the extent of the cost savings. To undertake an alternative strategy in relation to its role as supplier to the independent retailers requires that this results in a more profitable outcome, at least in the long run. Whether or not this is the case depends on, first, the extent of the flow of retail customers from the independents to Woolworths (such movement results in a loss of sales to Coles), and second, the extent to which the sales made from wholesaling to 
independent retailers are less profitable than supplying Coles's own vertically integrated retail outlets.

The possible outcomes from this option, relative to simply taking the extra profit associated with the cost saving, can be represented as follows:

\section{Table 1: Raising rivals' costs}

Wholesale profits from supply to independents relative to supply to Coles's own outlets

High flow

Unfavourable

Favourable

\section{Low flow}

Favourable

Favourable

Assume that Coles derives at least the same profit from supplying independent retailers as from supplying its own retailers (denoted as high profits in Table 1). If the proportion of former customers of the independent retailers shifting to Woolworths is high, it is not rational for Coles to raise supply costs and hence the prices of the independents. It will be worthwhile to do so only if the profits from supplying independent retailers are at least as high as from supplying Coles's own retail outlets and if the proportion of former customers of independents shifting to Woolworths is low.

Now assume that the profits from supplying independents are lower than from supplying its own vertically integrated outlets (denoted as low profits in Table 1). Then it will be in Coles's interests to raise rivals' costs to force them out of business irrespective of whether a high or a low proportion of customers shifts from independents to Woolworths. The difference in average store size suggests that supply costs to independent retailers are higher, so higher profits are likely to be derived from supplying Coles's own outlets. In addition, profits are derived only from wholesaling in the case of supply to independents, but are derived from both wholesaling and retailing in relation to Coles's own outlets.

Under a structuralist approach, after defining the market attention will focus on the consequences for competition and hence consumers of forcing the independent retailers out of the market. The high (and possibly heightened) barriers to entry, the vertical integration of the retail chains and the high level of market concentration suggest that, absent the independent retailers, Coles may be able to raise prices with a reasonable expectation that Woolworths will follow. Further, it is unlikely that much consideration would be given to Woolworths's responses to Coles's initiatives.

Now assume that for several years before the acquisition Coles spent heavily to establish a reputation for 'service and low everyday prices'. Consumers have to incur significant search costs if they want to be well-informed about grocery prices: the number of grocery items is very large, prices tend to change fairly frequently, and consumers do not make their purchasing decision on the basis of individual grocery items 
but on a package of groceries and associated services. Generally, consumers undertake only periodic searches because of the opportunity cost of search time, and rely instead on information conveyed by the reputation of the retailer.

However, if the retailer 'cheats' on its reputation, customers will go elsewhere and will be difficult to retrieve. The retailer would need to offer more than was originally promised in order to win them back. This could be a lengthy and costly process. Under these circumstances, it is much less likely that, following the exit of the independent retailers, Coles would be able to achieve a sustainable increase in prices. Maintaining its reputation would certainly be a constraint on Coles's pricing decisions. However, the constraint is not a structural one and is separate in time from the acquisition. It is not clear that the structuralist approach to analysing the acquisition would consider such a constraint.

\section{Consequences for Australian Competition Policy}

Incorporation of a strategic behaviour framework would not have necessarily significantly changed any previous decisions made by the ACT or the courts in Australia based on the QCMA approach. But this structural approach, with its focus on whether there is a causal sequence from market structure to conduct to performance, generates a significant potential risk of a wrong assessment of market conduct with respect to its effect on competition and hence as to whether there is a breach of the Trade Practices Act. Greater flexibility of analysis is needed.

While market behaviour should not be assessed without at least a careful consideration of the group or collective effects of market structure, the conduct of individual firms in the relevant institutional context - past, present and future, as firms jockey to make the most of their competitive environment - should become the prime focus of analysis. At the same time, the focus needs to be broadened away from the traditional area of the market to the firm's entire competitive environment, as the intricately intertwined operations of modern firms transcend the narrow market context.

The strategic behaviour approach adds several dimensions to the QCMA approach. It focuses more on individual behaviour than on group conduct; it looks to the future rather than to the past for its solutions; it recognises the need to examine the entire integrated pattern of a firm's behaviour across all the markets in which it operates; it recognises that there is no uniquely predictable outcome for any given situation; and it is more applicable to the analysis of misuse of market power scenarios under s.46 of the Trade Practices Act than is the QCMA approach. The central

\footnotetext{
${ }^{12}$ Feedback effects are allowed in the structural model, but usually are recognised only for their impact on structure.

${ }^{13}$

We are not implying here that analysis of issues brought under s.46 involves a structural approach. Rather, we simply make the point that analysis of competition matters in Australia based generally on a strategic behaviour framework would make for a more unified and consistent approach than is currently the case.
} 
task for those sitting in judgment on firms is to distinguish pro-competitive from anticompetitive strategic behaviour.

A recent unreported decision by the New Zealand High Court has laid a foundation for a departure from a pure market-power standard for testing whether conduct might substantially lessen competition. The Court acknowledged that 'even a monopolist has rights to compete', and cited with approval decisions in the US where it was concluded that a firm with lawful market power had no general duty to exercise competitive restraint and should be expected to compete aggressively. ${ }^{14}$ Of course, while it is encouraging to see this endorsement of the social and judicial acceptability of strategic behaviour, the Court did not provide (and, realistically, could not hope to provide) a definitive or universal test for distinguishing between pro-competitive and anti-competitive strategic behaviour. It all depends on the facts of each case.

As the noted British academic and consultant John Kay pointed out in his comments on an earlier version of this article presented at the Trade Practices Workshop, the key question to ask when a firm is charged with acting anti-competitively is whether its actions are essentially profitable in their own right (that is, independent of what rivals do), or whether profitability depends on the firm's expectations about the actions and reactions of its rivals. In other words, could the action be taken anyway, on a stand-alone basis, regardless of the responses of rivals, or alternatively, could such behaviour be observed in a market normally judged to be competitive? If the latter, the strategic behaviour is not likely to damage the competitive process.

This test cannot be taken as the exclusive test of whether strategic behaviour is anti-competitive. If this were the case, all technically efficient strategic behaviour could be found to be competitive, regardless of its outcome on structure. Also excluded from the reach of the law would be behaviour which is privately profitablc to the firm because of a combination of both efficiency and market power factors. Clearly a balancing of the two factors is necessary. Rather, a test based on strategic behaviour adds a further dimension to the determination of whether conduct substantially lessens competition.

\section{Conclusion}

Through strategic behaviour firms aim to achieve a sustainable, commercial advantage over their rivals. A firm engaged in strategic behaviour does not simply react to rivals' moves. The very essence of oligopoly is a conscious striving by firms to surpass their rivals, in the process securing as many sales as possible and a strong brand image, immune from rivals' strategies. Other firms, in order to survive, will react and seek to counter these actions. This is part of the vigorous process of competition which competition policy seeks to encourage and preserve.

In a ma rket where firms behave strategically and non-cooperatively, the structural features of the market may be altered or there may be non-structural con-

${ }^{14}$ Clear Communications Limited v Sky Network Television Limited \& Ors, New Zealand High Court, unreported judgment, 1 August 1997, at pp. 69-70. We are grateful to Frances Hanks for bringing this decision to our attention. 
straints on the conduct of firms. Under certain circumstances, strategic behaviour may result in the creation of market power which does not offer a stimulus to other firms to strive to match or surpass that firm's strategies, but which has the effect of foreclosing the market to new entrants: as in the case where strategic behaviour can seek deliberately to erect entry barriers even though currently they may not be present. ${ }^{15}$ When this occurs, it leads to a substantial lessening of competition.

On its own, a structuralist approach to analysing competition may focus on only one aspect of the firm's strategies; failure to analyse the entire strategy may suggest a substantial lessening of competition when none is likely, and vice versa. The danger of making such errors will be substantially reduced if firm conduct is assessed under an approach that takes into account all of the strategic activities engaged in by firms.

The recognition of strategic behaviour has far-reaching implications for competition policy and enforcement. Adoption of a strategic behaviour framework would undoubtedly extend the scope of conduct to be considered. Unilateral conduct by firms with reasonably small market shares might be judged to result in a substantial lessening of competition; more firms would be at risk of having action taken against their conduct. At the other extreme, properly addressing the strategic aspects of a market might eliminate concerns in some cases even where market concentration is high. But most important, incorporation of strategic behaviour into the analytical framework ensures that in competition analysis it is recognised that oligopoly and interdependence are not the exception but rather are the norm.

\section{References}

Australian Competition and Consumer Commission (ACCC) (1996), Merger Guidelines, Canberra.

Baker, J. (1997), 'Unilateral Competitive Effects Theories in Merger Analysis', Antitrust Journal 11(2): $21-2$.

Carlton, D. \& J. Perloff (1994), Modern Industrial Organization (2nd ed.), Harper Collins, New York.

Kay, J. (1993), Foundations of Corporate Success, Oxford University Press, Oxford.

Martin, S. (1993), Advanced Industrial Economics, Blackwell, Cambridge, Mass.

Porter, M. (1981), 'Strategic Interaction, Some Lessons from Industry Histories for Theory and Antitrust Policy', pp. 449-506 in S. Salop (ed.), Strategy, Predation, and Antitrust Analysis, Federal Trade Commission, Washington DC.

This article is a revised version of a paper presented to the 1997 Trade Practices Workshop conducted by the Business Law Section of the Law Council of Australia in Adelaide on 19 July 1997. We are especially grateful to John Kay for his support for the ideas presented here, and to Frances Hanks for her constructive comments on a previous draft.

15

All firms would like the quiet life which market power brings with it. But as market power cannot be exploited without the protection of entry barriers, seekers of market power need to engage in conduct designed to create such entry barriers. A firm can be lucky enough to be in the right place at the right time, as could happen, for example, with an advertising campaign for a small new firm which propels it into the limelight. But this is an example of conscious strategic behaviour. 